\title{
Inhibitory effects of curcumin on high glucose-induced damages: Implications for alleviating diabetic complications
}

\author{
Kyeong Yee $\mathrm{Kim}^{1}$, Choon Young Kim ${ }^{2 *}$ \\ ${ }^{1}$ Department of Biochemical Engineering, Seoil University, Seoul 02192, Korea \\ ${ }^{2}$ Department of Food and Nutrition, Yeungnam University, Gyeongsan 38541, Korea
}

\begin{abstract}
Hyperglycemia found in diabetes mellitus causes several physiological abnormalities including the formation of advanced glycation end products (AGEs) and oxidative stress. Accumulation of AGEs and elevation of oxidative stress plays major roles in the development of diabetic complications. Adiponectin secreted from adipocytes is known to improve insulin sensitivity and blood glucose level. Curcumin (CCM), a bioactive component of turmeric, has been reported as a potent antioxidant. Present work aimed to elucidate the roles of CCM in high glucose-induced protein glycation and intracellular events in mature adipocytes. The results demonstrated that CCM inhibited the formation of fluorescent AGEs by approximated 52\% at 3 weeks of bovine serum albumin (BSA) glycation with glucose. Correspondingly, CCM decreased the levels of fructosamine and a-dicarbonyl compounds during BSA glycation with glucose. These data suggested that CCM might be a new promising anti-glycation agent. Also, CCM reduced high glucose-induced oxidative stress in a dose dependent manner, whereas CCM treatment time-dependently elevated the expression of adiponectin gene in 3T3-L1 adipocytes. The findings from this study suggested the possibility of therapeutic use of CCM for the prevention of diabetic complications and obesity-related diseases.
\end{abstract}

Key words : curcumin, hyperglycemia, advanced glycation end products, oxidative stress, adiponectin

\section{Introduction}

The increasing prevalence of diabetes mellitus and diabetes complications reinforces concerns in public health. The major complications of diabetes are macrovascular disease, nephropathy, retinopathy, and neuropathy (1). Diabetic complications are developed during the progression of diabetes due to hyperglycemia. Hyperglycemia observed in patients with diabetes causes oxidative stress and protein glycation, thus leading diabetes complications (2).

Oxidative stress, the status of disturbance in the balance of antioxidants and pro-oxidants, damages healthy cells through oxidation of DNA, protein, and other macromolecules, implicating in the pathogenesis of various chronic diseases (3). Oxidative stress produced by hyperglycemia accelerates the

*Corresponding author. E-mail : cykim@yu.ac.kr Phone : 82-53-810-2871, fax : 82-53-810-4768

Received 11 May 2017; Revised 13 July 2017; Accepted 14 July 2017.

Copyright (c) The Korean Society of Food Preservation. All rights reserved. formation of advanced glycation end products (AGEs) (4).

The accumulation of AGEs from non-enzymatic glycation of protein has been implicated in pathophysiology associated with diabetes mellitus (5). In the initial stage of the non-enzymatic glycation of proteins, carbonyl group of the reducing sugar reacts with free amino groups of protein to form Schiff base, sequentially producing Amadori products. In the final stage, a-dicarbonyl compounds again react with free amino groups to form yellowish-brown, often fluorescent, irreversible compounds, usually called AGEs. AGEs cause various types of protein modifications, resulting in structural and functional impairments of proteins (6).

Meanwhile, hypoadiponectinemia appears to play an important role in insulin resistance and diabetes mellitus (7). Adiponectin, an adipokine expressed in adipose tissue, is known to sensitize the body to insulin (8). Thus, upregulation of adiponectin is a potential therapeutic target to alleviate insulin resistance and diabetes mellitus (9).

In order to prevent and/or ameliorate diabetic complications, it is important to control hyperglycemia or hyperglycemiainduced cellular events such as the formation of AGEs and 
oxidative stress. It is well known that antioxidants help reduce deterioration of hyperglycemia $(10,11)$. Curcumin (CCM), a yellow pigment in turmeric, is known to possess various biological activities including antioxidant, anti-inflammatory, anti-cancer, and anti-obese activities (12-14). The phenolic hydroxyl groups in CCM is responsible for the antioxidant properties while suppression of the nuclear factor kappa B signaling transduction pathways by CCM alleviates inflammation (12-13). Moreover, CCM exhibits anti-obesity activity through reducing adipocyte differentiation, one of the important target to prevent the development of obesity (14). Among natural compounds with antioxidant activity, CCM is one of the strongest antioxidant compounds, and thus CCM could have beneficial effects on hyperglycemia. Here inhibitory effects of CCM on high glucose-induced damages were investigated.

\section{Materials and Methods}

\section{Materials}

Bovine serum albumin (BSA) was obtained from Amresco (Solon, OH, USA). Curcumin (CCM), D-glucose, sodium azide, nitro blue tetrozolium (NBT), sodium formate, Girad-T solution, glyoxal, insulin, dexamethasone, isobutylmethylxanthine, and 2,7-dichlorodihydrofluorescein diacetate ( $\mathrm{H}_{2}$ DCFDA) were purchased from Sigma-Aldrich (St. Louis, MO, USA). Dulbecco's Modified Eagle's medium (DMEM), $0.25 \%$ trypsin-EDTA, sodium pyruvate, and penicillin/streptomycin were obtained from Fisher Scientific (Pittsburgh, PA, USA). Fetal calf serum (FCS) and fetal bovine serum (FBS) were obtained from PAA Laboratories (Pasching, Austria).

\section{Preparation of glycated BSA}

A physiological plasma glucose condition was mimicked for setting in vitro BSA glycation system. Mean blood glucose concentrations at 5,11 , and $25 \mathrm{mM}$ are considered as healthy fasting, healthy postprandial, and diabetic feeding concentration, respectively. Incubation time of 21 days was determined based on circulating half-life of plasma albumin. In order the examine the role of CCM on BSA glycation, BSA (42 g/L) was incubated with $25 \mathrm{mM}$ of glucose and $0.02 \%$ sodium azide in $0.2 \mathrm{M}$ phosphate buffer ( $\mathrm{pH}$ 6.8) with or without $1 \mathrm{mM}$ CCM. Reaction mixture was incubated at $37^{\circ} \mathrm{C}$ for 21 days. Samples were collected every week and stored frozen at $-70^{\circ} \mathrm{C}$ (Ultra-Low Temperature Freezer, Sanyo Electric Co., Ltd., Osaka, Japan) until analyzed.

\section{Estimation of fructosamine formation}

A colorimetric fructosamine assay using NBT reagents was used to estimate Amidori products, the early stage of the non-enzymatic glycation of proteins (15). Samples $(40 \mu \mathrm{L})$ were mixed with $160 \mu \mathrm{L}$ of $300 \mu \mathrm{M}$ NBT reagent in 100 $\mathrm{mM}$ sodium carbonate buffer $(\mathrm{pH} 10.35)$ and incubated for $30 \mathrm{~min}$ at room temperature. Absorbance of the reaction mixture was measured at $530 \mathrm{~nm}$ using a microplate spectrophotometer (Epoch, Bio-Tek Instruments, Inc. Winooski, VT, USA). The data was expressed as $\%$ of control.

\section{Evaluation of a-dicarbonyl compound formation}

Girard-T assay was used to detect a-dicarbonyl compound, the intermediate of glycation of protein (16). Samples (200 $\mu \mathrm{L})$ were incubated with $100 \mu \mathrm{L}$ of Girad-T solution and $1,700 \mu \mathrm{L}$ of $100 \mathrm{mM}$ sodium carbonate buffer ( $\mathrm{pH}$ 10.35) for $1 \mathrm{~h}$ at $25^{\circ} \mathrm{C}$. Absorbance of the reaction mixture was measured at $290 \mathrm{~nm}$ using an Ultraviolet-visible spectrophotometer (Hitachi, Ltd., Tokyo, Japan). A standard curve was prepared using glyoxal (GO) standards treated in the same way. The values of samples were calculated based on the equation of standard curve and data was expressed as $\mathrm{mg}$ GO equivalent $/ \mathrm{mL}$.

\section{Detection of AGE formation by fluorometric assay}

For detection of AGE formation, plate reader (VICTOR X3, PerkinElmer Singapore Pte Ltd., Turku, Finland) was employed (15). Fluorescence intensity from the glycated BSA was read at $460 \mathrm{~nm}$ after excitation at $355 \mathrm{~nm}$. Data was expressed as arbitrary units (AU).

\section{Cell culture condition}

The 3T3-L1 preadipocytes were cultured in DMEM containing $10 \%$ (v/v) FCS, $100 \mathrm{U} / \mathrm{mL}$ penicillin, $100 \mu \mathrm{g} / \mathrm{mL}$ streptomycin and $0.11 \mathrm{~g} / \mathrm{L}$ sodium pyruvate. Adipogenesis of 3T3-L1 preadipocytes were initiated in $10 \%$ (v/v) FBS with hormonal cocktail described in the paper (14). Day 10 of differentiated 3T3-L1 cells were tested for measurement of intracellular reactive oxygen species (ROS) and adiponectin.

\section{Determination of reactive oxygen species production}

The 3T3-L1 preadipocytes pre-treated with various concentrations of $\mathrm{CCM}$ for $30 \mathrm{~min}$ at $37^{\circ} \mathrm{C}$. After removal of CCM from the medium, $125 \mu \mathrm{M}$ of DCFDA was added directly to the medium for $1 \mathrm{~h}$ at $37^{\circ} \mathrm{C}$ (17). Intracellular 
ROS generated by high glucose was detected by plate reader (VICTORX3, PerkinElmer, Turku, Singapore).

Measurement of adiponectin gene expression

Total RNA was prepared from mature 3T3-L1 cells using TriZol according to the manufacturer's instructions (Invitrogen, Carlsbad, CA, US). cDNA was synthesized using Superscript II reverse transcriptase system (Invitrogen) and subjected to real-time RT-PCR using Power SYBR Green Master Mix (Applied Biosystems, Foster City, CA, US) (18). The specific primers used in quantitative RT-PCR are as follows: adiponectin (forward, $5^{\prime}$-GAT GCA GGT CTC TTG GTC CTA A-3 ' ; reverse, 5 ' -GGC CCT TCA GCT CCT GTC A-3 ') and $\beta$-actin (forward, 5-TGA CGG GGT CAC CCA CAC TGT GCC CAT CTA-3 ' ; reverse, $5^{\prime}$-CTA GAA GCA TTT GCG GTG GAC GAT GGA GGG-3 ' ).

\section{Statistical analysis}

Results were presented as mean \pm SE obtained at least three independent experiments with triplicate. Statistical analysis was performed using SAS 9.4 software (SAS Institute, Inc., Cary, NC, USA). Data were evaluated statistically using one-way analysis of variance (ANOVA) followed by Dunnett's multiple comparison method (Bonferroni's methods) to estimate significant difference between control and treatment groups. The statistical test is significant at the present level of $\mathrm{p}<0.05$.

\section{Results and Discussion}

Suppression of BSA glycation with glucose by curcumin addition

In order to evaluate inhibitory role of curcumin (CCM) on protein glycation, albumin, the most abundant protein in the blood, was chosen as a protein for the in vitro glycation reaction with high concentration of glucose. During 3 weeks of incubation of bovine serum albumin (BSA) and $25 \mathrm{mM}$ of glucose in the absence or presence of $1 \mathrm{mM} \mathrm{CCM}$, formation of advanced glycation end products (AGEs) was determined by a fructosamine assay, a-dicarbonyl compound measurement, and fluorescence analysis. CCM exhibited a potent inhibitory effect on AGEs formation in BSA glycation system (Fig. 1). The fructosamine assay for determining Amadori products generated in the early stage of the protein glycation suggested that CCM significantly suppressed Amadori product formation by approximately $50 \%$. Also,
CCM significantly mitigated the generation of a-dicarbonyl compounds, which are formed in the intermediate stage of

A

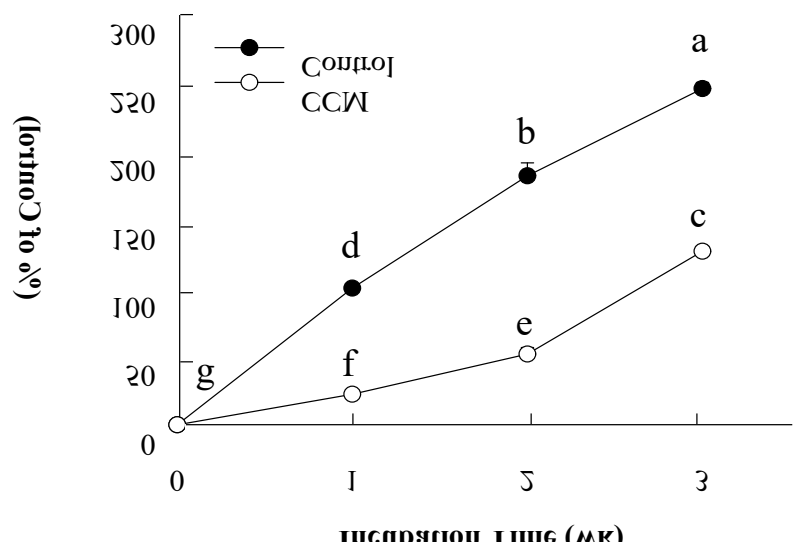

B

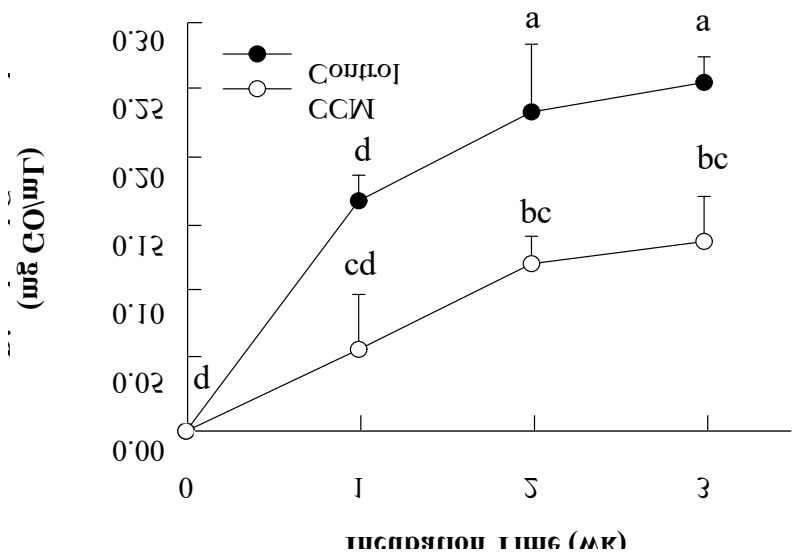

C

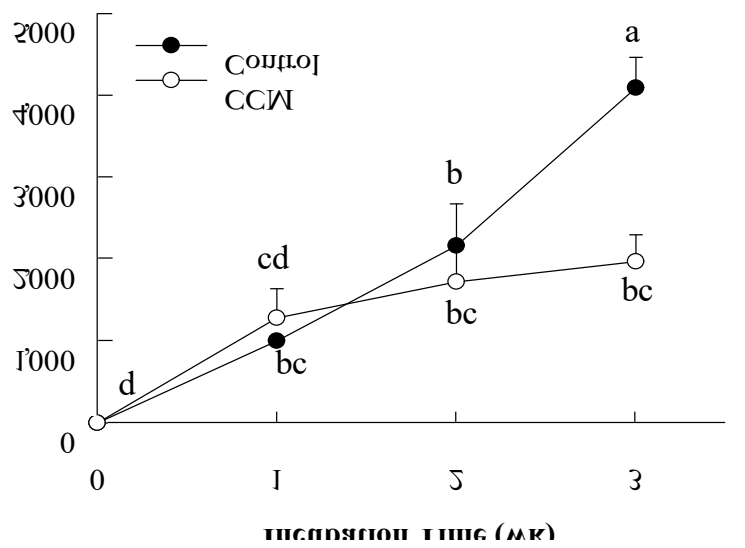

Fig. 1. Inhibitory effect of curcumin (CCM) on BSA glycation with glucose.

In order to estimate the role of CCM, $42 \mathrm{~g} / \mathrm{L}$ BSA was incubated in $25 \mathrm{mM}$ glucose with or without $1 \mathrm{mM} \mathrm{CCM}$ at $37^{\circ} \mathrm{C}$ for 3 weeks. Degree of BSA glycation was determined by measuring of the fructosamine (A), a-dicarbonyl compound (B), and fluorescence intensity $(\mathrm{C})$ at each week of incubation. 
glycation. As AGE formed, fluorescent signal produced from BSA glycation with glucose was gradually increased for 3 weeks of incubation. The results of 3 weeks of incubation showed that CCM treatment significantly reduced AGE formation by $52 \%$.

Since the level of blood glucose fluctuates throughout the day depending on meals and physical activity. In order to understand the effect of glucose concentration on generation of a-dicarbonyl compounds, increasing doses of glucose (5.6, 11 , and $25 \mathrm{mM}$ ) was incubated with BSA in the absence or presence of $1 \mathrm{mM} \mathrm{CCM}$. At 3 weeks of incubation, formation of a-dicarbonyl compounds was significantly elevated as a glucose dose increased (Fig. 2). However, CCM significantly diminished the production of a-dicarbonyl compounds due to high level of glucose.

It is well known that AGE formation stimulates diabetic complication and thus inhibition of AGE generation is one of the key targets to prevent the progression of diabetic complication. However, the development of anti-glycation agent is a challenge. Aminoguanidine, an AGE inhibitor, is no longer available as a drug due to multiple safety issue (19). Therefore, there has been an increasing interest in the use of natural compounds as anti-glycative agents. It has been reported that inhibition of AGE formation by guava leaf extract (15), cyaniding-3-rutinoside (20), feruloyl oligosaccharides (21), and vitamins and minerals including ascorbic acid, tocopherol, pyridoxal, and selenium (11). Similar with these compounds, CCM has a strong inhibitory activity in protein glycation under high concentration of glucose. Considering the fact that the formation of AGEs due to hyperglycemia

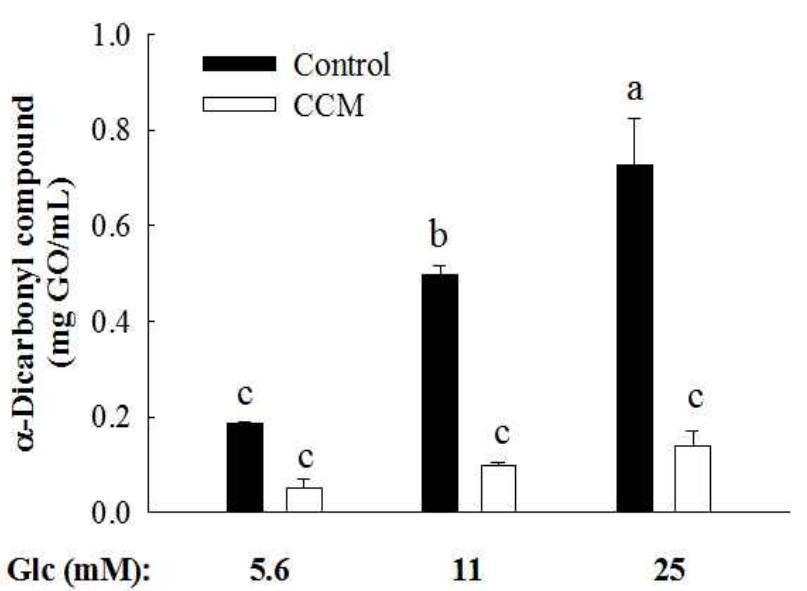

Fig. 2. Suppression of BSA glycation in various glucose (Glc) concentrations by curcumin (CCM) treatment.

BSA was incubated with glucose at concentration range of $5.6 \mathrm{mM}$ to $25.0 \mathrm{mM}$ in the absence or presence of $1 \mathrm{mM} \mathrm{CCM}$ at $37^{\circ} \mathrm{C}$. At 3 weeks of incubation, a-dicarbonyl compound was measured by Girad T assay. is a major contributor to lead diabetic complication in patient with diabetes, CCM can be used as a glycation inhibitor to prevent diabetic complications.

Inhibition of high glucose-induced intracellular oxidative stress by CCM treatment in mature 3T3-L 1 adipocytes

Hyperglycemia is known to induce intracellular oxidative stress, thus contributing the development of diabetic complications (2). In order to determine inhibitory effect of CCM treatment on high glucose-induced oxidative stress, intracellular reactive oxygen species (ROS) were estimated by DCFDA assay. Compared to low glucose (5.6 mM) treatment, high glucose $(25 \mathrm{mM})$ slightly elevated intracellular oxidative stress but CCM treatment alleviated high glucose-induced ROS production (Fig. 3). Inhibitory effect of CCM on high glucose-stimulated ROS production was found to be in a dose-dependent manner. Intracellular ROS generation was completely abolished by $\mathrm{CCM}$ at a concentration of $30 \mu \mathrm{M}$.

It is recommended for people with diabetes to take daily requirement of vitamin and mineral which have a strong antioxidant activity (22). Moreover, several studies suggested that compounds with combined antiglycative and antioxidant activities showed synergistic effects on not only preventing AGE production but also suppressing oxidative stress-induced toxicity. Based on our data that CCM has abilities to inhibit oxidative stress and protein glycation, it is believed that CCM could be a potent compound to prevent diabetic complications.

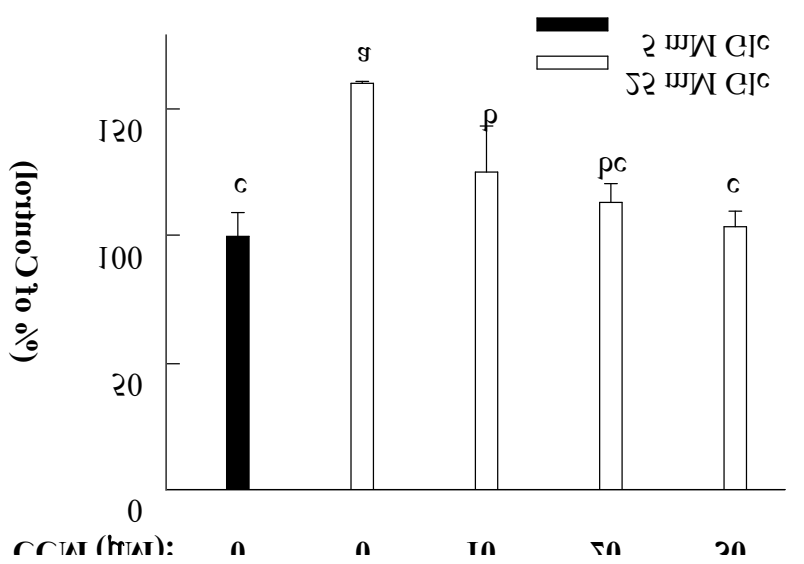

Fig. 3. Reduction of high glucose (Glc)-induced intracellular oxidative stress by curcumin (CCM) treatment in mature 3T3-L1 adipocytes.

Mature 3T3-L1 adipoctyes were pre-treated with various concentrations $(0,10,20$ and $30 \mu \mathrm{M})$ of CCM for $1 \mathrm{~h}$ and then incubated in low $(5 \mathrm{mM})$ and high $(25 \mathrm{mM})$ glucose medium for $6 \mathrm{~h}$. Intracellular reactive oxygen species (ROS) production was detected using DCFDA assay. 
Among natural compounds, green tea is known to help diabetic complications because it has protective activity against protein oxidation and glycation (10).

Induction of adiponectin gene expression by CCM treatment in mature 3T3-L1 adipocytes

Since adiponectin, a protein hormone secreted from adipocytes, improves glucose regulation, upregulation of adiponectin expression elicits protective function against type 2 diabetes (23). In order to test whether CCM treatment in adipocytes stimulates adiponectin expression, the adiponectin gene expression in 3T3-L1 adipocytes was detected by quantitative RT-PCR. The results reveal that $20 \mu \mathrm{M}$ of CCM treatment in mature adipocytes significantly increased adiponectin gene expression in a time-dependent manner (Fig. 4). Results showed that CCM treatment for $24 \mathrm{~h}$ and $48 \mathrm{~h}$ significantly increased the level of adiponectin gene by approximately 1.2 folds and 1.5 folds, respectively.

Many studies suggested that natural compounds are able to increase adiponectin expression. Phloretin $(50 \mu \mathrm{M})$, a flavonoids found in apples and strawberries, increased adiponectin mRNA expression in mature 3T3-L1 adipocytes by 2.3 folds (24). In addition, naringin, a flavanone glycoside found in grapes and citrus fruits, is also known to increase serum adiponectin and ameliorate insulin resistance in a rat model of type 2 diabetes (25). Since the protein level of adiponectin in plasma and mRNA expression of adiponectin in adipocytes are reversely correlated with obesity and insulin resistance (9), administration or upregulation of adiponectin by dietary compounds may reverse insulin resistance and

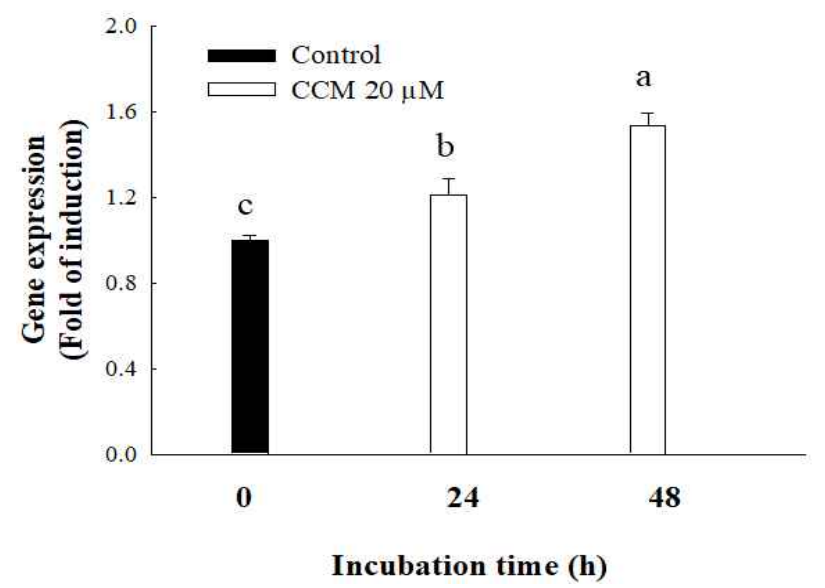

Fig. 4. Upregulation of adiponectin gene expression by curcumin (CCM) in mature 3T3-L1 adipocytes.

Mature 3T3-L1 adipocytes were treated with $20 \mathrm{mM}$ of CCM for 24 and $48 \mathrm{~h}$. Gene expression of adiponectin was determined by quantitative RT-PCR. Level of gene expression was normalized by $\beta$-actin gene and expressed by fold of induction diabetes. Therefore, it is possible that CCM alleviates the symptoms of diabetes and diabetic complications. Even though our data show that CCM stimulated adiponectin mRNA expression in 3T3-L1 adipocytes, further study is necessary to confirm the physiological relevance of this result.

\section{Summary}

Preventive activities of CCM on high glucose-induced damages were determined by the level of BSA glycation with glucose, intracellular ROS production, and adiponectin gene expression in mature adipocytes. CCM inhibited formations of fructosamine, a-dicarbonyl compounds, AGEs in $\mathrm{BSA} /$ glucose system during the 3 weeks of incubation. Regardless of glucose concentration, CCM significantly reduced the level of a-dicarbonyl compounds. High concentration $(25 \mathrm{mM})$ of glucose-induced intracellular ROS production, whereas CCM suppressed high glucose-induced intracellular ROS production in a dose-dependent manner. Moreover, CCM upregulated the gene expression of adiponectin, an adipocyte-specific secretory protein. The results of this study suggested that CCM could be beneficial for preventing the development of diabetic complication.

\section{Acknowledgments}

The present research has been conducted by the Research Grant of Seoil University in 2017.

\section{References}

1. Brownlee M (2001) Biochemistry and molecular cell biology of diabetic complications. Nature, 414, 813-820

2. Giacco F, Brownlee M (2010) Oxidative stress and diabetic complications. Circ Res, 107, 1058-1070

3. Finkel T, Holbrook NJ (2000) Oxidants, oxidative stress and the biology of ageing. Nature, 408, 239-247

4. Yan SD, Schmidt AM, Anderson GM, Zhang J, Brett J, Zou YS, Pinsky D, Stern D (1994) Enhanced cellular oxidant stress by the interaction of advanced glycation end products with their receptors/binding proteins. J Biol Chem, 269, 9889-9897

5. Zhang Q, Ames JM, Smith RD, Baynes JW, Metz TO (2009) A perspective on the Maillard reaction and the 
analysis of protein glycation by mass spectrometry: probing the pathogenesis of chronic disease. J Proteome Res, 8, 754-769

6. Neelofar K, Arif Z, Alam K, Ahmad J (2016) Hyperglycemia induced structural and functional changes in human serum albumin of diabetic patients: a physico-chemical study. Mol Biosyst, 12, 2481-2489

7. Weyer C, Funahashi T, Tanaka S, Hotta K, Matsuzawa Y, Pratley RE, Tataranni PA (2001) Hypoadiponectinemia in obesity and type 2 diabetes: close association with insulin resistance and hyperinsulinemia. J Clin Endocrinol Metab, 86, 1930-1935

8. Hu E, Liang P, Spiegelman BM (1996) AdipoQ is a novel adipose-specific gene dysregulated in obesity. J Biol Chem, 271, 10697-10703

9. Yamauchi T, Kamon J, Waki H, Terauchi Y, Kubota N, Hara K, Mori Y, Ide T, Murakami K, TsuboyamaKasaoka N, Ezaki O, Akanuma Y, Gavrilova O, Vinson C, Reitman ML, Kagechika H, Shudo K, Yoda M, Nakano Y, Tobe K, Nagai R, Kimura S, Tomita M, Froguel P, Kadowaki T (2001) The fat-derived hormone adiponectin reverses insulin resistance associated with both lipoatrophy and obesity. Nat Med, 7, 941-946

10. Nakagawa T, Yokozawa T, Terasawa K, Shu S, Juneja LR (2002) Protective activity of green tea against free radical-and glucose-mediated protein damage. J Agric Food Chem, 50, 2418-2422

11. Vinson JA, Howard TB (1996) Inhibition of protein glycation and advanced glycation end products by ascorbic acid and other vitamins and nutrients. The $\mathrm{J}$ Nutr Biochem, 7, 659-663

12. Shishodia S, Sethi G, Aggarwal BB (2005) Curcumin: Getting back to the roots. Ann N Y Acad Sci, 1056, 206-217

13. Anand P, Thomas SG, Kunnumakkara AB, Sundaram C, Harikumar KB, Sung B, Tharakan ST, Misra K, Priyadarsini IK, Rajasekharan KN, Aggarwal BB (2008) Biological activities of curcumin and its analogues (Congeners) made by man and Mother Nature. Biochem Pharmacol, 76, 1590-1611

14. Kim CY, Le TT, Chen C, Cheng JX, Kim KH (2011) Curcumin inhibits adipocyte differentiation through modulation of mitotic clonal expansion. J Nutr Biochem, 22, 910-920
15. Wu JW, Hsieh CL, Wang HY, Chen HY (2009) Inhibitory effects of guava (Psidium guajava L.) leaf extracts and its active compounds on the glycation process of protein. Food Chem, 113, 78-84

16. Mitchel R, Birnboim HC (1977) The use of Girard-T reagent in a rapid and sensitive method for measuring glyoxal and certain other a-dicarbonyl compounds. Anal Biochem, 81, 47-56

17. Chen CY, Abell AM, Moon YS, Kim KH (2012) An advanced glycation end product (AGE)-receptor for AGEs (RAGE) axis restores adipogenic potential of senescent preadipocytes through modulation of p53 protein function. J Biol Chem, 287, 44498-44507

18. Kim CY, Bordenave N, Ferruzzi MG, Safavy A, Kim $\mathrm{KH}$ (2011) Modification of curcumin with polyethylene glycol enhances the delivery of curcumin in preadipocytes and its antiadipogenic property. J Agric Food Chem, 59, 1012-1019

19. Keen H, Fukker JH, Menzinger G (1997) Early closure of European Pimagedine trial. Lancet, 350, 214-215

20. Thilavech T, Ngamukote S, Abeywardena M, Adisakwattana $S$ (2015) Protective effects of cyanidin-3-rutinoside against monosaccharides-induced protein glycation and oxidation. Int J Biol Macromol, 75, 515-520

21. Wang J, Sun B, Cao Y, Tian Y (2009) Protein glycation inhibitory activity of wheat bran feruloyl oligosaccharides. Food Chem, 112, 350-353

22. Evert AB, Boucher JL, Cypress M, Dunbar SA, Franz MJ, Mayer-Davis EJ, Neumiller JJ, Nwankwo R, Verdi CL, Urbanski P, Yancy WS (2013) Nutrition therapy recommendations for the management of adults with diabetes. Diabetes Care, 36, 3821-3842

23. Kadowaki T, Yamauchi T (2005) Adiponectin and adiponectin receptors. Endocr Rev, 26, 439-451

24. Hassan M, El Yazidi C, Landrier JF, Lairon D, Margotat A, Amiot MJ (2007) Phloretin enhances adipocyte differentiation and adiponectin expression in 3T3-L1 cells. Biochem Biophys Res Commun, 361, 208-213

25. Sharma AK, Bharti S, Ojha S, Bhatia J, Kumar N, Ray R, Kumari S, Arya DS (2011) Up-regulation of PPARy, heat shock protein-27 and-72 by naringin attenuates insulin resistance, $\beta$-cell dysfunction, hepatic steatosis and kidney damage in a rat model of type 2 diabetes. Br J Nutr, 106, 1713-1723 